\title{
Functions of nuclear actin-binding proteins in human cancer (Review)
}

\author{
XINYI YANG ${ }^{1,2}$ and YING LIN ${ }^{1,2}$ \\ ${ }^{1}$ Guangdong Provincial Key Laboratory of Malignant Tumor Epigenetics and Gene Regulation; \\ ${ }^{2}$ Department of Gastroenterology and Hepatology, Sun Yat-sen Memorial Hospital, \\ Sun Yat-sen University, Guangzhou, Guangdong 510120, P.R. China
}

Received February 16, 2017; Accepted November 10, 2017

DOI: $10.3892 / \mathrm{ol} .2017 .7658$

\begin{abstract}
Nuclear actin-binding proteins (ABPs) perform distinguishable functions compared with their cytoplasmic counterparts in extensive activities of living cells. In addition to the ability to regulate actin cytoskeleton dynamics, nuclear ABPs are associated with multiple nuclear biological processes, including chromatin remodeling, gene transcriptional regulation, DNA damage response, nucleocytoplasmic trafficking and nuclear structure maintenance. The nuclear translocation of ABPs is affected by numerous intracellular or extracellular stimuli, which may lead to developmental malformation, tumor initiation, tumor progression and metastasis. Abnormal expression of certain ABPs have been reported in different types of cancer. This review focuses on the newly identified roles of nuclear ABPs in the pathological processes associated with cancer.
\end{abstract}

\section{Contents}

1. Introduction

2. Actin and actin-binding proteins (ABPs) in the nucleus

3. Nuclear ABPs in cancer cells

4. Conclusion and perspectives

\section{Introduction}

Actin is one of the most abundant proteins identified in almost all eukaryotic cells, and it is a highly conserved protein during evolution (1). Actin-binding proteins (ABPs) refer to proteins

Correspondence to: Dr Ying Lin, Department of Gastroenterology and Hepatology, Sun Yat-sen Memorial Hospital, Sun Yat-sen University, 107 West Yanjiang Road, Guangzhou, Guangdong 510120, P.R. China

E-mail: linwy@mail.sysu.edu.cn

Key words: actin-binding protein, nuclear, actin, transcription, cancer that contain actin-binding domains that interact with actin. They can bind to actin monomers, actin polymers or both (2).

Early studies have focused on the biological features and physiological mechanisms of cytoplasmic actin. Therefore, ABPs were considered to be distributed only in the cytoplasm and associated with the organization of actin cytoskeleton (3). In the cytoplasm, actin is associated with numerous cellular activities, including sustaining cellular morphology, determining cellular organelle distribution, mediating intracellular transfer, endocy tosis and exocytosis, cell division, cell migration and adhesion (4-8). Meanwhile, ABPs regulate actin cytoskeletal structure by modulating actin filament cross-linking into networks or depolymerizing into monomers, allowing actin to switch between the polymeric (F-actin form, filamentous actin) and monomeric state (G-actin form, globular actin) $(2,9)$.

However, recent studies $(10,11)$ indicate that a great number of actin and ABPs exist in the nucleus. Nuclear actin and nuclear ABPs exhibit nuclear-specific functions that are different from those in the cytoplasm. Although the precise biological mechanisms remain elusive, we are fortunate to uncover several observations (12). This review aims to present up-to-date discoveries of nuclear actin and nuclear ABPs in the field of cancer research.

\section{Actin and actin-binding proteins (ABPs) in the nucleus}

Studies in the recent decades provide a plethora of evidence that has broadened our horizon on the functions of nuclear actin and nuclear ABPs in the eukaryotic cell life (12-14). Since the existence of nuclear actin was confirmed, subsequent studies also established the presence of ABPs in the nucleus $(12,14,15)$. The very first nuclear ABP was reported as early as 1987 , henceforth, the rest of the ABP family in the nucleus has come to light comprising of proflilin, anillin, flightless I (Fli I), filamin $\alpha$ $(\mathrm{FLN} \alpha), \alpha$-actinins, myosins, gelsolin and ezrin-radixin-moesin proteins $(12,13,16,17)$. Although these ABPs are primarily in the cytoplasm, they can translocate into the nucleus under certain circumstances, for example, extracellular stimuli (stress), hormone stimulation and intracellular signaling (16).

In the nucleus, actin is associated with chromatin remodeling, DNA replication, DNA repair, gene transcriptional regulation, RNA processing, nuclear protein transportation and maintenance of nuclear structure, for instance, the nuclear 
envelope assembly $(12,18-20)$. Nuclear ABPs are closely associated to nuclear actin and implicated in various nuclear activities. ABPs promote actin filament nucleation or sequestering, manipulate nuclear actin dynamics and determine the ratio of nuclear to cytoplasmic actin (13). Therefore, ABPs directly or indirectly associate with chromatin remodeling, DNA replication, transcription, DNA repair, nucleocytoplasmic transport and maintenance of nuclear structure integrity $(12,13,21)$. Furthermore, nuclear actin is required by all three RNA polymerases in transcriptional activation (22-24). The study by Miyamoto and Gurdon (25) mentions the major function of nuclear actin and ABPs in transcriptional regulation and nuclear reprogramming.

In eukaryotic cells, the cytoplasm and nucleus are separated by the nuclear envelope, which is a double membrane barrier. Trafficking of proteins and other molecules between these two compartments occurs by passing through the nuclear pore complex. Additionally, cytoplasmic ABPs can interact with the nuclear receptor in the cytoplasm, form complexes and facilitate nuclear translocation. Therefore, ABPs mediate transcriptional activation of nuclear receptors. These nuclear receptors include the glucocorticoid and estrogen receptor, androgen receptor (AR), thyroid receptor and peroxisome proliferator-activated receptor-c (26-28). Furthermore, they are associated with transcriptional activation of multiple genes and are involved in a spectrum of functions, including cell proliferation, differentiation and apoptosis $(21,29,30)$.

\section{Nuclear ABPs in cancer cells}

Numerous ABPs demonstrate the ability to shuttle between the cytoplasm and nucleus via different mechanisms. The question remains whether it is the shuttling of ABPs between different cellular compartments that is linked to pathological behaviors, including abnormal cell development and differentiation, carcinogenesis and metastasis. However, this needs to be clarified. The theory that ABPs in the nucleus affect the aforementioned pathological processes is intriguing. In the sections, the nuclear ABPs that are associated with chromatin remodeling, transcriptional regulation, DNA damage repair, protein nucleocytoplasmic shuttling and nuclear structure maintenance in human cancer cells are summarized in Table I and Fig. 1.

Fli I homolog (FLII), with a C-terminal gelsolin-like actin-binding domain, is a member of the gelsolin protein superfamily. FLII interacts with BAF53, a subunit of the SWItch/Sucrose Non-Fermentable chromatin-remodeling complex, and recruits the latter to the promoter and enhancer regions of the trefoil factor 1 gene, an estrogen receptor $(E R \alpha)$ target gene (31) (Fig. 1). FLII also regulates chromatin accessibility for the binding of RNA polymerase II and other transcriptional coactivators to the promoter and enhancer of other ER $\alpha$ target genes, including growth regulation by estrogen in breast cancer 1, continuous traumatic stress disorder and MYC in MCF-7 breast cancer cells. In addition, FLII promotes the hormone-dependent growth of breast cancer cells (32).

Villin is a tissue-specific ABP predominantly expressed in the epithelium, including the gastrointestinal tract and digestive organs. Overexpression of villin is reported in tissues of Barrett's metaplasia, gastric and colorectal adenocarcinoma $(33,34)$. Furthermore, villin is distributed in the cytoplasm and nucleus and cytoplamic-nuclear transport of villin keeps the system dynamically stable. It migrates to the nucleus upon stimulation, including hypoxia and injury. Another postulation is that tyrosine phosphorylation of villin may prompt its gathering in the nucleus. A study reveals that villin in the nucleus can interact with ZBRK1 [also called zinc finger and breast cancer type 1 (BRCA1)-interaction protein], a transcriptional corepressor and also a ligand of the human Slug promoter, thus regulating the activity of Slug and gene expression (34).

The villin-ZBRK1 complex eliminates the corepressor effect of ZBRK1 and upregulates Slug expression. Slug is a crucial transcriptional regulator of epithelial-mesenchymal transition (EMT). Therefore, nuclear villin performs an important role in inducing EMT, which is considered essential in tumorigenesis (34), invasiveness and metastasis. A previous study demonstrates that severe combined immunodeficiency mice injected with xenografts derived from five colon cancer cell lines developed tumors in 21 days at a $100 \%$ frequency, and by staining with villin antibodies, the xenografts reveal strong nuclear accumulation of villin (34). Furthermore, villin expression is observed in gastric, colorectal, pancreatic, biliary, liver, renal, cervical, endometrioid, lung and other types of cancer (34-36), particularly with propensity for metastasis and poor prognosis.

$\alpha$-actinin 4 (ACTN4), a member of the ABP family, is a regulator of gene transcription that is presumably mediated by nuclear hormone receptors. Although the majority of ACTN4 is located in the cytoplasm, the proportion of ACTN4 in the nucleus is unneglectable. ACTN4 binds to the nuclear receptors in a hormone-dependent manner. Furthermore, ACTN4 is a coactivator of the estrogen receptor $\alpha(E R-\alpha)$ that regulates target gene transcription in MCF-7 breast cancer cells, subsequently promoting tumor cell proliferation (37). Overexpression of ACTN4 in the nucleus increases the expression of progesterone receptors and antigen related to ER (pS2), and target genes of ER- $\alpha$ (Fig. 1). Furthermore, it can interact with the pS2 promoter and potentiate estradiol (E2)-induced transcription. Additionally, it interacts with the AR and functions as a co-regulator of AR-mediated transcription (38).

Nuclear ACTN4 serves as a transcriptional coactivator for nuclear factor $\kappa$-light-chain enhancer of activated B-cell (NF- $\kappa B$ ) (39). NF- $\kappa \mathrm{B}$ activation in ER $\alpha$-negative breast cancer promotes cancer cell proliferation (40). Furthermore, ACTN4 also interacts with histone deacetylase 7 (HDAC7), a transcriptional corepressor of myocyte enhancer factor 2 (MEF2), competitively inhibiting the repressing effect of HDAC7 and potentiating MEF2 transcription activity (41). ACTN4 interacts with HDAC7 by its C-terminal calmodulin $(\mathrm{CaM})$-like domain, and activates ER $\alpha$ transcription, which contributes to tumorigenesis in breast cancer (42). In addition, elevated levels of ACTN4 are widely identified in other malignancies, including colorectal, pancreatic, prostate and ovarian cancer, salivary gland carcinoma and esophageal cancer $(38,42-46)$.

FLN $\alpha$, also called ABP-280, is a scaffold protein. Filamin deficit is prevalent among carcinomas, including colon, prostate and breast cancer. It is verified that FLN $\alpha$ acts as a promoter in cancer metastasis and invasion in the cytoplasm, 
Table I. Summary of nuclear functions of actin-binding proteins in human cancer.

\begin{tabular}{|c|c|c|c|c|}
\hline Nuclear function & $\mathrm{ABP}$ & Mechanism & Tumor & (Refs.) \\
\hline $\begin{array}{l}\text { Chromatin } \\
\text { remodeling }\end{array}$ & $\begin{array}{l}\text { Flightless I } \\
\text { homolog }\end{array}$ & $\begin{array}{l}\text { Recruits chromatin } \\
\text { remodeling complex }\end{array}$ & Breast cancer & $(31,32)$ \\
\hline \multirow[t]{4}{*}{$\begin{array}{l}\text { Transcriptional } \\
\text { regulation }\end{array}$} & Villin & $\begin{array}{l}\text { Interacts with } \\
\text { transcriptional } \\
\text { corepressor }\end{array}$ & $\begin{array}{l}\text { Lung, gastric, } \\
\text { colorectal, pancreatic, } \\
\text { biliary, liver, renal, } \\
\text { cervical and endometrioid cancer }\end{array}$ & $(33-36)$ \\
\hline & $\alpha$-actinin 4 & $\begin{array}{l}\text { Interacts with } \\
\text { nuclear receptor } \\
\text { (act as a coactivator); } \\
\text { interacts with } \\
\text { transcriptional corepressor }\end{array}$ & $\begin{array}{l}\text { Breast, prostate, ovarian, } \\
\text { colorectal, pancreatic and } \\
\text { esophageal cancer, and } \\
\text { salivary gland carcinoma }\end{array}$ & $(37-39,41-46)$ \\
\hline & Filamin $\alpha$ & $\begin{array}{l}\text { Interact with } \\
\text { transcription factors }\end{array}$ & $\begin{array}{l}\text { Colon, breast and } \\
\text { prostate cancer }\end{array}$ & $(47-49)$ \\
\hline & Transgelin & $\begin{array}{l}\text { Speculated to act } \\
\text { as a transcriptional regulator }\end{array}$ & Colorectal cancer & $(57,58)$ \\
\hline \multirow[t]{2}{*}{$\begin{array}{l}\text { DNA damage } \\
\text { response }\end{array}$} & Filamin $\alpha$ & $\begin{array}{l}\text { Participates in double } \\
\text { strand break repair (DSBR) }\end{array}$ & $\begin{array}{l}\text { Breast cancer, } \\
\text { certain melanomas }\end{array}$ & $(61,63)$ \\
\hline & Nesprin-1 & $\begin{array}{l}\text { Participates in the DNA } \\
\text { damage response (DDR), } \\
\text { DNA mismatch repair (MMR) }\end{array}$ & Liver cancer & (64) \\
\hline $\begin{array}{l}\text { Protein nuclear } \\
\text { translocation }\end{array}$ & Nesprin-2 & $\begin{array}{l}\text { Participates in protein nuclear } \\
\text { localization }\end{array}$ & Breast cancer & $(65-67)$ \\
\hline \multirow[t]{2}{*}{$\begin{array}{l}\text { Nuclear structure } \\
\text { maintenance }\end{array}$} & Nesprin-1 & $\begin{array}{l}\text { Constitutes the linker of } \\
\text { nucleoskeleton and } \\
\text { cytoskeleton (LINC) complex }\end{array}$ & $\begin{array}{l}\text { Lung and pancreatic } \\
\text { cancer }\end{array}$ & (69) \\
\hline & Nesprin-2 & Constitutes LINC complex & $\begin{array}{l}\text { Breast and colorectal } \\
\text { cancer, head and neck } \\
\text { squamous cell carcinoma }\end{array}$ & $(70-72)$ \\
\hline
\end{tabular}

$\mathrm{ABP}$, actin-binding protein.

while it functions as a tumor suppressor in the nucleus (47). Furthermore, cytoplasmic FLN $\alpha$ interacts with a number of proteins, for example, $\beta 1$-integrin, phosphatidylinositols and small GTPases, which facilitate cell adhesion and migration. Furthermore, nuclear FLN $\alpha$ interacts with transcription factors and the associate transcription machinery subsequently restrains cell migration and represses cell growth. A previous study demonstrates that nuclear FLN $\alpha$ prohibits ribosome RNA transcription by interacting with RNA polymerase I (48). In addition, nuclear FLN $\alpha$ binds to the AR and modulates the nuclear translocation of the latter, thus regulates AR-induced gene expression. AR is a steroid nuclear receptor and closely associated with prostate cancer. Nuclear FLN $\alpha$ inhibits AR target gene transcription, thus negatively regulating cancer development (49).

Transgelin is an ABP mostly distributed in the cytoplasm of fibroblasts and several epithelial cells (50). Its expression is often altered in human types of cancer (51-55). Previous research by this group (56) revealed that activated AKT and c-jun NH2-terminal kinases promote the expression of transgelin in the cytoplasm and contribute to colorectal cancer progression. Additionally, it is revealed that transgelin was located in the cytoplasm and nucleus of colorectal cancer cells (57). Overexpression of transgelin in human colon cancer cells affects the expression of $\sim 250$ other transcripts and enhances the metastatic behavior (58). Thus, it is speculated that transgelin is another transcriptional regulator within the ABP family.

The recovery of DNA damage is essential in the maintenance of genome integrity. The nuclear FLN $\alpha$ is associated with DNA damage repair (59). By contacting BRCA1 and breast cancer type 2 (BRCA2), nuclear FLN $\alpha$ is involved in the process of homologous recombinational and non-homologous DNA repair (60). Furthermore, FLN $\alpha$ interacts with BRCA1 with its extreme C-terminus and mediates BRCA1 and Rad51 foci formation following DNA damage (Fig. 1). In addition, the lack of FLN $\alpha$ may contribute to predisposition to breast cancer (61). In double strand break repair (DSBR), FLN $\alpha$ interacts with BRCA2 and subsequently forms the repair complex (Fig. 1). The deficiency in FLN $\alpha$ makes the cells susceptible to ionizing radiation and delays the recovery from $\mathrm{G} 2 / \mathrm{M}$ arrest, which may trigger the incidence of cancer (60-63). Measurement of FLN $\alpha$ expression reveals that FLN $\alpha$ is negative in several melanomas (63). In the absence of FLN $\alpha$, cells 


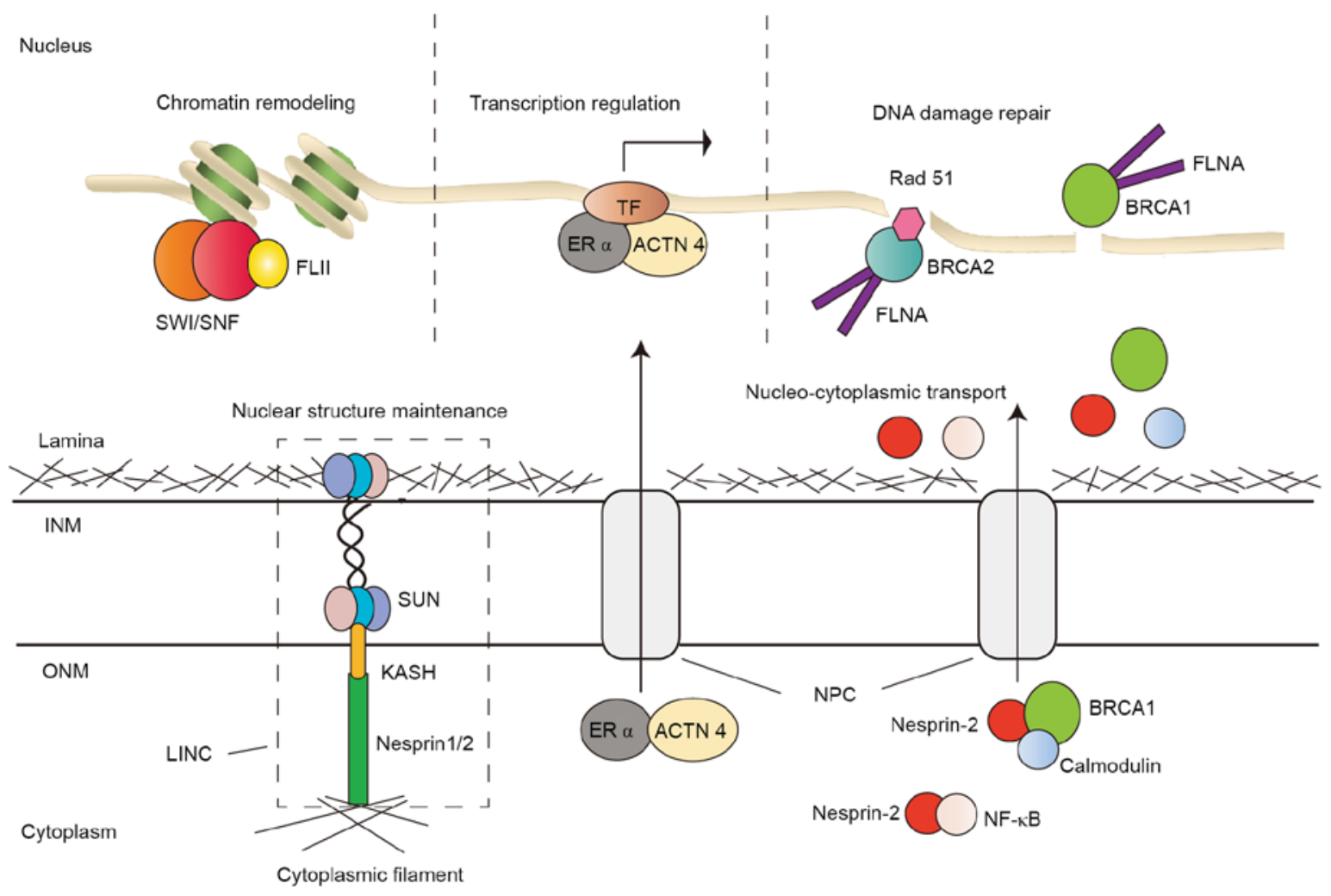

Figure 1. Illustrations of ABPs in the nucleus. ABPs are involved in chromatin remodeling, gene transcriptional regulation, DNA damage repair, nucleocytoplasmic transport and nuclear structure maintenance. ABP, actin-binding protein; INM, inner nuclear membrane; ONM, outer nuclear membrane; NPC, nuclear pore complex; LINC, linker of nucleoskeleton and cytoskeleton complex; SUN, SUN domain proteins; KASH, KASH domain; FLII, flightless I homolog; SWI/SNF, SWItch/Sucrose Non-Fermentable chromatin remodeling complex; ACTN 4, $\alpha$-actinin 4; ER $\alpha$, estrogen receptor $\alpha$; TF, transcription factor; FLN $\alpha$, filamin $\alpha$; NF- $\kappa$ B, nuclear factor $\kappa$-light-chain enhancer of activated B-cells; BRCA2, breast cancer type 2; BRCA1, breast cancer type 1 .

impair to recover from DNA damage and incline to accumulate genetic mutations and initiate tumorigenesis.

Nesprin-1, also known as Enaptin, is a nuclear envelope protein, consisting of a C-terminal KASH domain, a long spectrin repeat region and an $\mathrm{N}$-terminal $\mathrm{F}$-actin binding domain. Novel observations indicate that Nesprin-1 is involved in the DNA damage response and DNA mismatch repair (MMR), thus maintaining genetic stability (64). The study indicates that Nesprin-1 interacts with the DNA MMR proteins, MSH2 and MSH6, and regulates the expression level and function of these proteins, which are associated to DSBR. Reduction of Nesprin-1 may lead to deficiency in correcting DNA damage, therefore triggering tumorigenesis and accelerating tumor progression. Consistent with this, Nesprin-1 expression significantly decreases in liver cancer and numerous other types of human cancer (64). Nesprin-2 is a nuclear membrane protein of the nuclear envelope spectrin-repeat (nesprin) family, which contains an actin-binding domain. Loss of Nesprin-2 is associated with less nuclear accumulation of c-Fos, mothers against decapentaplegic homolog (SMAD) 2, 3 and 4, holding back the course of nuclear translocation $(65,66)$. Furthermore, the latest studies imply that Nesprin-2 is a prerequisite for the nuclear transport of certain proteins, for example, BRCA1 and NF- $\mathrm{\kappa B}$ (Fig. 1). The nuclear localization of BRCA1 is regulated by a RAN-independent $\mathrm{Ca}^{2+} / \mathrm{CaM}$ mediated machinery in which Nesprin-2 is necessary (66). Additionally, abnormality in Nesprin-2 nuclear trafficking results in impaired nuclear translocation and mislocalization of BRCA1. Downregulation of Nesprin-2 is revealed in breast cancer tissue (67). Therefore, disturbance of nuclear translocation of certain proteins by the ABPs may be associated to a number of diseases, including cancer (66).

Nesprins, a family of nuclear envelope proteins, together with SUN domain proteins, form the core of the linker of nucleoskeleton and cytoskeleton (LINC) complex. As a key component of the LINC complex, nesprins tether nuclei to the cytoskeleton and are essential in the maintenance of the nuclear architecture (Fig. 1). Loss of nesprins leads to risk of nuclear structural instability, including nuclear shape, size and chromatin organization, which is implicated in tumorigenesis (68). Furthermore, nesprin-1 downregulation is reported in lung cancer, and synaptic nuclear envelope protein 1 gene mutation is observed in pancreatic cancer with metastasis (69).

Spectrin repeat containing, nuclear envelope protein 2 abnormality is revealed in breast and colorectal cancer, and head and neck squamous cell carcinoma (70-72). One possible mechanism is that nesprin downregulation modulates nuclear stiffness via the LINC complex, and increases nuclear malleability for cells to migrate through restricted tissue spaces (69).

\section{Conclusion and perspectives}

ABPs have been revealed in both the cytoplasm and nucleus of eukaryotic cells. These proteins share an actin-binding 
calponin homology domain, exhibit different functions and are involved in diverse activities in the two cellular compartments. Numerous studies observe a significant proportion of ABP shuttle between the cytoplasm and the nucleus. Cytoplasmic ABPs may translocate into the nucleus in response to the alternation of the extracellular microenvironment, including hypoxia, inflammation and injury. The subcellular localization of ABPs is associated with the onset and development of various pathogenesis and carcinogenesis processes. Recent observations (73-75) demonstrate that nuclear ABPs may be involved in chromatin remodeling, function as transcriptional regulators, are involved in the DNA damage response and DNA mismatch repair, mediate protein nuclear translocation and maintain nuclear structural stability. Altogether, the nuclear ABPs maintain the genomic integrity and reduce cellular oncogenic potential; whereas mutations and deficiencies of nuclear ABPs contribute to tumorigenesis and metastasis.

Although the comprehensive molecular mechanism of specific nuclear ABPs remains elusive, the understanding of the association between nuclear ABPs and relevant diseases is extended. The investigation of ABPs' nuclear function and their effects on cancer remains underway and lots of questions remain to be answered. These studies will help to identify novel therapeutic targets in fighting against cancer in the near future.

\section{Acknowledgements}

The National Natural Science Foundation of China (grant no. 81641179, YL) and the Natural Science Foundation of Guangdong Province (grant no. 2017A030313603, YL) supported the present study. Grant (2013) 163 from the Key Laboratory of Malignant Tumor Molecular Mechanism and Translational Medicine of Guangzhou Bureau of Science and Information Technology, and grant no. KLB09001 from the Key Laboratory of Malignant Tumor Gene Regulation and Target Therapy of Guangdong Higher Education Institutes also supported the present study.

\section{References}

1. Pollard TD and Cooper JA: Actin and actin-binding proteins A critical evaluation of mechanisms and functions. Annu Rev Biochem 55: 987-1035, 1986.

2. dos Remedios CG, Chhabra D, Kekic M, Dedova IV, Tsubakihara M, Berry DA and Nosworthy NJ: Actin binding proteins: Regulation of cytoskeletal microfilaments. Physiol Rev 83: 433-473, 2003.

3. Hartwig JH, Tyler J and Stossel TP: Actin-binding protein promotes the bipolar and perpendicular branching of actin filaments. J Cell Biol 87: 841-848, 1980.

4. Hall A: Rho GTPases and the actin cytoskeleton. Science 279: 509-514, 1998.

5. Amann KJ and Pollard TD: Cellular regulation of actin network assembly. Curr Biol 10: R728-R730, 2000.

6. Vasioukhin V, Bauer C, Yin M and Fuchs E: Directed actin polymerization is the driving force for epithelial cell-cell adhesion. Cell 100: 209-219, 2000.

7. Winder SJ and Ayscough KR: Actin-binding proteins. J Cell Sci 118: 651-654, 2005.

8. Pollard TD and Cooper JA: Actin, a central player in cell shape and movement. Science 326: 1208-1212.

9. Weston L, Coutts AS and La Thangue NB: Actin nucleators in the nucleus: An emerging theme. J Cell Sci 125: 3519-3527, 2012

10. Fairley EA, Kendrick-Jones J and Ellis JA: The Emery-Dreifuss muscular dystrophy phenotype arises from aberrant targeting and binding of emerin at the inner nuclear membrane. J Cell Sci 112: 2571-2582, 1999 .
11. Tse WT, Tang J, Jin O, Korsgren C, John KM, Kung AL, Gwynn B, Peters LL and Lux SE: A new spectrin, beta IV, has a major truncated isoform that associates with promyelocytic leukemia protein nuclear bodies and the nuclear matrix. J Biol Chem 276: 23974-23985, 2001.

12. Castano E, Philimonenko VV, Kahle M, Fukalová J, Kalendová A, Yildirim S, Dzijak R, Dingová-Krásna H and Hozák P: Actin complexes in the cell nucleus: New stones in an old field. Histochem Cell Biol 133: 607-626, 2010.

13. Kristo I, Bajusz I, Bajusz C, Borkuti P and Vilmos P: Actin, actin-binding proteins and actin-related proteins in the nucleus. Histochem Cell Biol 145: 373-388, 2016.

14. Hofmann WA: Cell and molecular biology of nuclear actin. Int Rev Cell Mol Biol 273: 219-263, 2009.

15. de Lanerolle P and Serebryannyy L: Nuclear actin and myosins: Life without filaments. Nat Cell Biol 13: 1282-1288, 2011.

16. Gettemans J, Van Impe K, Delanote V,Hubert T, Vandekerckhove J and De Corte V: Nuclear actin-binding proteins as modulators of gene transcription. Traffic 6: 847-857, 2005.

17. Rando OJ, Zhao K and Crabtree GR: Searching for a function for nuclear actin. Trends Cell Biol 10: 92-97, 2000

18. Bettinger BT, Gilbert DM and Amberg DC: Actin up in the nucleus. Nat Rev Mol Cell Biol 5: 410-415, 2004.

19. Blessing CA, Ugrinova GT and Goodson HV: Actin and ARPs: Action in the nucleus. Trends Cell Biol 14: 435-442, 2004.

20. Miralles F and Visa N: Actin in transcription and transcription regulation. Curr Opin Cell Biol 18: 261-266, 2006.

21. Zheng B, Han M, Bernier M and Wen JK: Nuclear actin and actin-binding proteins in the regulation of transcription and gene expression. FEBS J 276: 2669-2685, 2009.

22. Philimonenko VV, Zhao J, Iben S, Dingová H, Kyselá K, Kahle M, Zentgraf H, Hofmann WA, de Lanerolle P, Hozák P and Grummt I: Nuclear actin and myosin I are required for RNA polymerase I transcription. Nat Cell Biol 6: 1165-1172, 2004.

23. Hofmann WA, Stojiljkovic L, Fuchsova B, Vargas GM, Mavrommatis E, Philimonenko V, Kysela K, Goodrich JA, Lessard JL,Hope TJ, et al: Actin is part of pre-initiation complexes and is necessary for transcription by RNA polymerase II. Nat Cell Biol 6: 1094-1101, 2004.

24. Hu P, Wu S and Hernandez N: A role for beta-actin in RNA polymerase III transcription. Genes Dev 18: 3010-3015, 2004.

25. Miyamoto K and Gurdon JB: Transcriptional regulation and nuclear reprogramming: Roles of nuclear actin and actin-binding proteins. Cell Mol Life Sci 70: 3289-3302, 2013.

26. Ting HJ, Yeh S, Nishimura K and Chang C: Supervillin associates with androgen receptor and modulates its transcriptional activity. Proc Natl Acad Sci USA 99: 661-666, 2002.

27. Nishimura K, Ting HJ, Harada Y, Tokizane T, Nonomura N, Kang HY, Chang HC, Yeh S, Miyamoto H, Shin M, et al: Modulation of androgen receptor transactivation by gelsolin: A newly identified androgen receptor coregulator. Cancer Res 63: 4888-4894, 2003.

28. Yang Z, Chang YJ, Miyamoto H, Ni J, Niu Y, Chen Z, Chen YL, Yao JL, di Sant'Agnese PA and Chang C: Transgelin functions as a suppressor via inhibition of ARA54-enhanced androgen receptor transactivation and prostate cancer cell growth. Mol Endocrinol 21: 343-358, 2007.

29. Baek SH, Ohgi KA, Nelson CA, Welsbie D, Chen C, Sawyers CL, Rose DW and Rosenfeld MG: Ligand-specific allosteric regulation of coactivator functions of androgen receptor in prostate cancer cells. Proc Natl Acad Sci USA 103: 3100-3105, 2006.

30. Wang F, Liu XQ, Li H, Liang KN, Miner JN, Hong M, Kallel EA, van Oeveren A, Zhi L and Jiang T: Structure of the ligand-binding domain (LBD) of human androgen receptor in complex with a selective modulator LGD2226. Acta Crystallogr Sect F Struct Biol Cryst Commun 62: 1067-1071, 2006.

31. Won Jeong K, Chodankar R, Purcell DJ, Bittencourt D and Stallcup MR: Gene-specific patterns of coregulator requirements by estrogen receptor-alpha in breast cancer cells. Mol Endocrinol 26: 955-966, 2012.

32. Jeong KW: Flightless I (Drosophila) homolog facilitates chromatin accessibility of the estrogen receptor $\alpha$ target genes in MCF-7 breast cancer cells. Biochem Biophys Res Commun 446: 608-613, 2014.

33. Khurana S: Structure and function of villin. In: Aspects of the Cytoskeleton. Khurana S (ed). Elsevier New York, pp89-1159, 2006.

34. Patnaik S, George SP, Pham E, Roy S, Singh K, Mariadason JM and Khurana S: By moonlighting in the nucleus, villin regulates epithelial plasticity. Mol Biol Cell 27: 535-548, 2016. 
35. Shillingford NM, Calicchio ML, Teot LA, Boyd T, Kurek KC, Goldsmith JD, Bousvaros A, Perez-Atayde AR and Kozakewich HP: Villin immunohistochemistry is a reliable method for diagnosing microvillus inclusion disease. Am J Surg Pathol 39: 245-250, 2015.

36. Yang Z: The utility of villin and mammaglobin in the differential diagnosis between intrahepatic cholangiocarcinoma and breast cancer. Appl Immunohistochem Mol Morphol 23: 19-25, 2015.

37. Khurana S, Chakraborty S, Cheng X, Su YT and Kao HY: The actin-binding protein, actinin alpha 4 (ACTN4), is a nuclear receptor coactivator that promotes proliferation of MCF-7 breast cancer cells. J Biol Chem 286: 1850-1859, 2011.

38. Jasavala R, Martinez H, Thumar J, Andaya A, Gingras AC, Eng JK, Aebersold R, Han DK and Wright ME: Identification of putative androgen receptor interaction protein modules: Cytoskeleton and endosomes modulate androgen receptor signaling in prostate cancer cells. Mol Cell Proteomics 6: 252-271, 2007.

39. Zhao X, Hsu KS, Lim JH, Bruggeman LA and Kao HY: $\alpha$-Actinin 4 potentiates nuclear factor $\kappa$-light-chain-enhancer of activated $\mathrm{B}$-cell $(\mathrm{NF}-\kappa \mathrm{B})$ activity in podocytes independent of its cytoplasmic actin binding function. J Biol Chem 290: 338-349, 2015.

40. Biswas DK, Shi Q, Baily S, Strickland I, Ghosh S, Pardee AB and Iglehart JD: NF-kappa B activation in human breast cancer specimens and its role in cell proliferation and apoptosis. Proc Natl Acad Sci USA 101: 10137-10142, 2004.

41. Chakraborty S, Reineke EL, Lam M, Li X, Liu Y, Gao C, Khurana S and Kao HY: Alpha-actinin 4 potentiates myocyte enhancer factor- 2 transcription activity by antagonizing histone deacetylase 7. J Biol Chem 281: 35070-35080, 2006

42. Hsu KS and Kao HY: Alpha-actinin 4 and tumorigenesis of breast cancer. Vitam Horm 93: 323-351, 2013.

43. Hara T, Honda K, Shitashige M, Ono M, Matsuyama H, Naito K, Hirohashi S and Yamada T: Mass spectrometry analysis of the native protein complex containing actinin-4 in prostate cancer cells. Mol Cell Proteomics 6: 479-491, 2007.

44. Yamamoto S, Tsuda H, Honda K, Kita T, Takano M, Tamai S, Inazawa J, Yamada $\mathrm{T}$ and Matsubara O: Actinin-4 expression in ovarian cancer: A novel prognostic indicator independent of clinical stage and histological type. Mod Pathol 20: 1278-1285, 2007.

45. Kikuchi S, Honda K, Tsuda H, Hiraoka N, Imoto I, Kosuge T, Umaki T, Onozato K, Shitashige M, Yamaguchi U, et al: Expression and gene amplification of actinin-4 in invasive ductal carcinoma of the pancreas. Clin Cancer Res 14: 5348-5356, 2008

46. Honda K: The biological role of actinin-4 (ACTN4) in malignant phenotypes of cancer. Cell Biosci 5: 41, 2015.

47. Savoy RM and Ghosh PM: The dual role of filamin A in cancer: Can't live with (too much of) it, can't live without it. Endocr Relat Cancer 20: R341-R356, 2013

48. Deng W, Lopez-Camacho C, Tang JY, Mendoza-Villanueva D, Maya-Mendoza A, Jackson DA and Shore P: Cytoskeletal protein filamin A is a nucleolar protein that suppresses ribosomal RNA gene transcription. Proc Natl Acad Sci USA 109: 1524-1529, 2012

49. Loy CJ, Sim KS and Yong EL: Filamin-A fragment localizes to the nucleus to regulate androgen receptor and coactivator functions. Proc Natl Acad Sci USA 100: 4562-4567, 2003.

50. Lawson D, Harrison M and Shapland C: Fibroblast transgelin and smooth muscle SM22alpha are the same protein, the expression of which is down-regulated in many cell lines. Cell Motil Cytoskeleton 38: 250-257, 1997.

51. Shields JM, Rogers-Graham K and Der CJ: Loss of transgelin in breast and colon tumors and in RIE-1 cells by Ras deregulation of gene expression through Raf-independent pathways. J Biol Chem 277: 9790-9799, 2002

52. Sitek B, Lüttges J, Marcus K, Klöppel G, Schmiegel W, Meyer HE, Hahn SA and Stühler K: Application of fluorescence difference gel electrophoresis saturation labelling for the analysis of microdissected precursor lesions of pancreatic ductal adenocarcinoma. Proteomics 5: 2665-2679, 2005.

53. Mikuriya K, Kuramitsu Y,Ryozawa S, Fujimoto M, Mori S,OkaM, Hamano K, Okita K, Sakaida I and Nakamura K: Expression of glycolytic enzymes is increased in pancreatic cancerous tissues as evidenced by proteomic profiling by two-dimensional electrophoresis and liquid chromatography-mass spectrometry/mass spectrometry. Int J Oncol 30: 849-855, 2007.

54. Huang Q, Huang Q, Chen W, Wang L, Lin W, Lin J and Lin X: Identification of transgelin as a potential novel biomarker for gastric adenocarcinoma based on proteomics technology. J Cancer Res Clin Oncol 134: 1219-1227, 2008.
55. Sun X, Zhang H, Luo L, Zhong K, Ma Y, Fan L, Fu D and Wan L: Comparative proteomic profiling identifies potential prognostic factors for human clear cell renal cell carcinoma. Oncol Rep 36: 3131-3138, 2016

56. Zhou H, Zhang Y, Chen Q and Lin Y: AKT and JNK signaling pathways increase the metastatic potential of colorectal cancer cells by altering transgelin expression. Dig Dis Sci 61: 1091-1097, 2016.

57. Lin Y, Buckhaults PJ, Lee JR, Xiong H, Farrell C, Podolsky RH, Schade RR and Dynan WS: Association of the actin-binding protein transgelin with lymph node metastasis in human colorectal cancer. Neoplasia 11: 864-873, 2009.

58. Zhou HM, Fang YY, Weinberger PM, Ding LL, Cowell JK, Hudson FZ, Ren M, Lee JR, Chen QK, Su H, et al: Transgelin increases metastatic potential of colorectal cancer cells in vivo and alters expression of genes involved in cell motility. BMC Cancer 16: 55, 2016

59. Yuan $\mathrm{Y}$ and Shen $\mathrm{Z}$ : Interaction with BRCA2 suggests a role for filamin-1 (hsFLNa) in DNA damage response. J Biol Chem 276: 48318-48324, 2001 .

60. Yue J, Huhn S and Shen Z: Complex roles of filamin-A mediated cytoskeleton network in cancer progression. Cell Biosci 3: 7, 2013.

61. Velkova A, Carvalho MA, Johnson JO, Tavtigian SV and Monteiro AN: Identification of Filamin A as a BRCA1-interacting protein required for efficient DNA repair. Cell cycle 9: 1421-1433, 2010.

62. Meng X, Yuan Y, Maestas A and Shen Z: Recovery from DNA damage-induced $G 2$ arrest requires actin-binding protein filamin-A/actin-binding protein 280. J Biol Chem 279: 6098-6105, 2004

63. Yue J, Wang Q, Lu H, Brenneman M, Fan F and Shen Z: The cytoskeleton protein filamin-A is required for an efficient recombinational DNA double strand break repair. Cancer Res 69: 7978-7985, 2009.

64. Sur I, Neumann S and Noegel AA: Nesprin-1 role in DNA damage response. Nucleus 5: 173-191, 2014.

65. Rashmi RN, Eckes B, Glöckner G, Groth M, Neumann S, Gloy J, Sellin L, Walz G, Schneider M, Karakesisoglou I, et al: The nuclear envelope protein Nesprin-2 has roles in cell proliferation and differentiation during wound healing. Nucleus 3: 172-186, 2012.

66. Kelkar P, Walter A, Papadopoulos S, Mroß C, Munck M, Peche VS and Noegel AA: Nesprin-2 mediated nuclear trafficking and its clinical implications. Nucleus 6: 479-489, 2015.

67. Matsumoto A, Hieda M, Yokoyama Y, Nishioka Y, Yoshidome K, Tsujimoto $\mathrm{M}$ and Matsuura N: Global loss of a nuclear lamina component, lamin A/C, and LINC complex components SUN1, SUN2 and nesprin-2 in breast cancer. Cancer Med 4: 1547-1557, 2015.

68. Neumann S and Noegel AA: Nesprins in cell stability and migration. Adv Exp Med Biol 773: 491-504, 2014.

69. Cartwright $S$ and Karakesisoglou I: Nesprins in health and disease. Semin Cell Dev Biol 29: 169-179, 2014.

70. Sjöblom T, Jones S, Wood LD, Parsons DW, Lin J, Barber TD, Mandelker D, Leary RJ, Ptak J, Silliman N, et al: The consensus coding sequences of human breast and colorectal cancers. Science 314: 268-274, 2006

71. Chittenden TW, Howe EA, Culhane AC, Sultana R, Taylor JM, Holmes C and Quackenbush J: Functional classification analysis of somatically mutated genes in human breast and colorectal cancers. Genomics 91: 508-511, 2008.

72. Stransky N, Egloff AM, Tward AD, Kostic AD, Cibulskis K, Sivachenko A, Kryukov GV, Lawrence MS, Sougnez C, McKenna A, et al: The mutational landscape of head and neck squamous cell carcinoma. Science 333: 1157-1160, 2011.

73. Zhang P, Sridharan D and Lambert MW: Nuclear $\alpha$ spectrin differentially affects monoubiquitinated versus non-ubiquitinated FANCD2 function after DNA interstrand cross-link damage. J Cell Biochem 117: 671-683, 2016.

74. Almuzzaini B, Sarshad AA, Farrants AK and Percipalle P: Nuclear myosin 1 contributes to a chromatin landscape compatible with RNA polymerase II transcription activation. Bmc Biol 13: 35, 2015.

75. Savoy RM, Chen L, Siddiqui S, Melgoza FU, Durbin-Johnson B, Drake C, Jathal MK, Bose S, Steele TM, Mooso BA, et al: Transcription of Nrdp1 by the androgen receptor is regulated by nuclear filamin A in prostate cancer. Endocr Relat Cancer 22: 369-386, 2015 